\title{
Donor and recipient genotype and heterosis effects on survival and prenatal growth of transferred mouse embryos
}

\author{
D. Pomp*, D. E. Cowley†, E. J. Eisen*, W. R. Atchley† and \\ D. Hawkins-Brown $\dagger$ \\ Departments of * Animal Science and $\dagger$ Genetics, North Carolina State University, Raleigh, \\ NC 27695, USA
}

\begin{abstract}
Summary. Reciprocal embryo transfers amongst two inbred strains $(\mathrm{C} 3 \mathrm{HeB} / \mathrm{FeJ}$ and SWR/J) and their F1 cross (C3SWF1) were used to examine donor and recipient genotype and heterosis effects on survival and prenatal growth of mouse embryos. Among inbred strains, significant recipient genotype effects were detected for both embryo survival $(P<0.01)$ and prenatal growth $(P<0.05)$, while no donor genotype effects were observed. The recipient effect on overall embryo survival was due to a higher proportion of $\mathrm{C} 3 \mathrm{H}$ recipients maintaining pregnancy to term than SWR recipients $(P<0.01)$, rather than survival within litters. Irrespective of their own genotype, embryos developing in $\mathrm{C} 3 \mathrm{H}$ uteri achieved larger body weights $(P<0.01)$ and longer tail lengths $(P<0.05)$ at birth than did embryos developing in SWR uteri. Recipient heterosis was not significant, while donor heterosis was significant for prenatal growth traits $(P<0.001)$.
\end{abstract}

Keywords: embryo survival; uterus; maternal effects; genetics; mice

\section{Introduction}

Survival and prenatal growth of mammalian embryos are influenced by genotype of the embryo, genotype of the uterus providing the developmental environment and their interactions. Embryo transfer technology enables experimental manipulation of genotypic combinations of embryos (donors) and uteri (recipients), affording unique opportunities to study genetic control of embryonic survival and growth. In addition, information regarding genetic variability and heterosis in efficiency of embryo transfer would be useful for research and animal breeding programmes.

Embryo transfer in mice has been previously utilized as a research tool to study embryonic and uterine genotype effects on prenatal survival in selected (Brumby, 1960; Moore et al., 1970a, b; Moler et al., 1981) and inbred (Fekete, 1947; Baunack et al., 1986) mice. Iida et al. (1987) examined heterosis in survival of transferred mouse embryos.

In the present study, a replicated embryo transfer experiment was conducted to partition and quantify donor and recipient genotype effects. Reciprocal embryo transfers between two inbred mouse strains $(\mathrm{C} 3 \mathrm{HeB} / \mathrm{FeJ}$ and $\mathrm{SWR} / \mathrm{J})$ and their $\mathrm{F}_{1}$ hybrid (C3SWF1) allowed estimation of genetic variation among strains as well as heterosis effects on survival and prenatal growth. In addition, the influence of histoincompatibility between conceptus and mother was studied. Effects of embryonic and uterine genotypes on post-natal development of mice produced by embryo transfer are presented elsewhere (Cowley et al., 1989). 


\section{Materials and Methods}

\section{Experimental design}

Mice from two inbred strains ( $\mathrm{C} 3 \mathrm{HeB} / \mathrm{FeJ}$ and $\mathrm{SWR} / \mathrm{J})$ and their $\mathrm{F}_{1}$ hybrid cross (C3SWF1) were obtained from The Jackson Laboratory (Bar Harbor, ME, USA). They were housed in cages on hardwood chips with food (Breeder Blox; Wayne, St Louis, MO, USA) and water supplied ad libitum. Room temperature was maintained between 23 and $26^{\circ} \mathrm{C}$, with a controlled 12-h light:12-h dark cycle with lights on at 07:00 h.

Reciprocal embryo transfers were performed between embryos and uteri of $\mathrm{C} 3 \mathrm{H}$, SWR and C3SWF1 mice. The two parental inbred strains were chosen because they differ in adult body size and are not closely related through genealogy. Atchley et al. (1988) have shown that C3H and SWR mice differ at many major gene loci and vary widely in polygenic traits. Embryos of C3SWF1 genotype were obtained by mating SWR males to $\mathrm{C} 3 \mathrm{H}$ females. Thus, embryos representing 3 nuclear genotypes developed in 3 uterine genotypes in a factorial design (Fig. 1), providing tests of donor and recipient genotype and heterosis effects on survival and growth of transferred embryos. $\mathrm{C} 3 \mathrm{H}$ and SWR mice differ at the H-2 MHC complex, as well as at multiple minor histocompatibility loci (Green, 1981), enabling testing of effects of histoincompatibility between conceptus and mother.

\section{Donor genotype Recipient genotype}

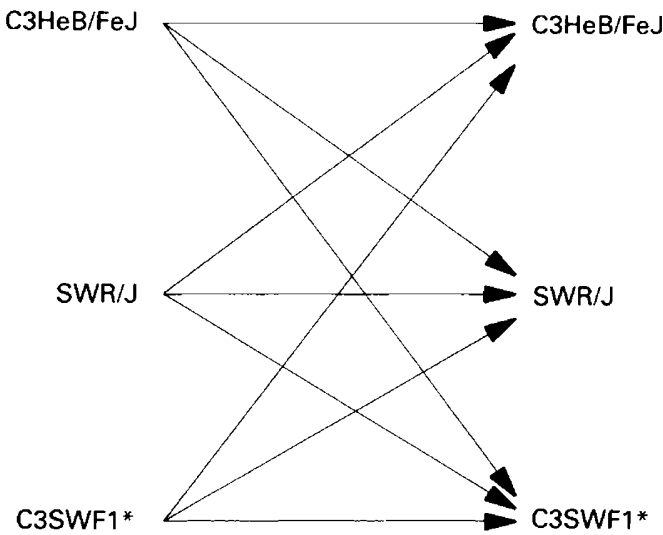

Fig. 1. Experimental design for reciprocal embryo transfers to study donor (embryo) and recipient (uterus) genotype and heterosis effects on survival and prenatal growth in mice. ${ }^{*} \mathrm{C} 3 \mathrm{HeB} / \mathrm{FeJ}$ female $\times \mathrm{SWR} / \mathrm{J}$ male.

\section{Experimental protocol}

Donor females (6-8 weeks old) were superovulated without regard to stage of the oestrous cycle with 5 i.u. PMSG followed $48 \mathrm{~h}$ later by $5 \mathrm{i}$.u. hCG. After hCG injection, females were caged singly with a male and successful matings were determined by the presence of copulatory plugs the following morning ( $18 \mathrm{~h}$ after hCG). At $90 \mathrm{~h}$ after hCG, donor females were killed by cervical dislocation and their uteri excised and placed in warm, gassed $\left(5 \% \mathrm{CO}_{2}\right.$ in air) Whitten's medium (Whitten, $1971 ; 3 \mathrm{mg} \mathrm{BSA} / \mathrm{ml}$ ). Morulae and blastocysts were flushed from the uteri, counted and held in Whitten's medium at $37^{\circ} \mathrm{C}$ in $5 \% \mathrm{CO}_{2}$ in air until transfer. Only embryos of good to excellent morphological quality (Lindner \& Wright, 1983) were used for transfer. Time between flushing and transfer did not exceed 15 min.

Pseudopregnancy was induced in recipient females (7-9 weeks old) by mating with vasectomized ICR males of proven sterility. Recipients were at Day 2 or 3 of pseudopregnancy at time of transfer. Recipients were anaesthetized by injection of pentobarbitone sodium (Butler Co., Columbus, OH, USA; $0.06 \mathrm{mg} / \mathrm{g}$ body weight), and 4-7 embryos were transferred in small amounts $(2-5 \mu \mathrm{l})$ of Whitten's medium via a drawn out glass capillary pipette to each uterine horn.

Beginning at 12 days after transfer, recipient females were checked twice daily for parturition. On the day of parturition, litter size (live and dead young), and weights and tail lengths of young were recorded.

To maintain relatively homogeneous age ranges of donor and recipient females, the experiment was conducted in two replicates of approximately equal magnitude. Transfers in the second replicate began less than 1 week after the final transfers of the first replicate. 


\section{Statistical methods}

Donor and recipient heterosis effects were calculated for all traits as the percentage difference of the hybrid strain, C3SWF1, from the mean of the parental inbred strains C3H and SWR $[100(\mathrm{C} 3 \mathrm{SWF} 1-(\mathrm{SWR}+\mathrm{C} 3 \mathrm{H})(0 \cdot 5)) /$ $(\mathrm{SWR}+\mathrm{C} 3 \mathrm{H})(0 \cdot 5)]$. Statistical significance of heterosis effects and differences between inbred strains were tested using linear contrasts for the following traits: (1) hormone-induced ovulation rate of donors; (2) body weight of recipients at time of transfer; (3) proportion of recipients producing litters; (4) proportion of transferred embryos carried to term (separate analyses for all recipients and recipients producing litters); and (5) body weight and tail length of young on day of birth.

To adjust for heterogeneity of variance of data generated as proportions and different numbers of embryos transferred to recipients, values on proportions of transferred embryos carried to term were transformed to weighted angles (Freeman \& Tukey, 1950) before analysis. Analyses were by weighted-least-squares for categorical data (Grizzle $e t$ al., 1969) and/or least-squares procedures for unequal subclass numbers (Harvey, 1979). Replicate effects were tested for all traits and were significant only for the proportion of recipient females producing litters. The statistical model included fixed effects of donor and recipient genotype and their interaction, and a random residual. Models for body weight and tail length of young at birth included sex as a fixed effect and litter size as a covariate. Effects of stage of pseudopregnancy of recipient females (Day 2 or 3) were not significant for any of the traits and were not included in the analyses.

\section{Results}

\section{Ovulation rate and body weight}

Hormone-induced ovulation rate of donors (Table 1) was variable across genotypes, with a range from 3 to 30 embryos recovered per female. This high variability was not surprising in view of use of sexually mature donors and injection of hormones without regard to stage of the oestrous cycle. SWR mice exhibited a higher ovulation rate $(27 \%)$ than did $\mathrm{C} 3 \mathrm{H}$ mice, although this difference was not significant $(P>0.05)$. Heterosis was slightly negative $(-6.5 \% ; P>0.05)$.

Body weights of recipients on the day of embryo transfer (Table 1) were higher in $\mathrm{C} 3 \mathrm{H}$ than SWR mice $(22.2 \% ; P<0.01)$. Heterosis was positive and large $(15.4 \% ; P<0.01)$.

Table 1. Least-squares means and s.e. of hormone-induced ovulation rate (6-8-week-old donors) and body weight (7-9-week-old recipients) utilized for embryo transfers

\begin{tabular}{lcc}
\hline Strain & $\begin{array}{c}\text { Ovulation rate } \\
\text { (no. of donors) }\end{array}$ & $\begin{array}{c}\text { Body weight } \\
\text { (no. of recipients) }\end{array}$ \\
\hline C3H & $10.91 \pm 1.38^{\mathrm{a}}(23)$ & $24.45 \pm 0.53^{\mathrm{a}}(19)$ \\
SWR & $13.86 \pm 1.44^{\mathrm{a}}(21)$ & $19.56 \pm 0.32^{\mathrm{b}}(20)$ \\
C3SWF1 & $11.58 \pm 1.19^{\mathrm{Ns}}(31)$ & $25.38 \pm 0.34^{*}(23)$ \\
\hline
\end{tabular}

${ }^{a, b}$ Within columns, parental inbred strain (C3H, SWR) means with no superscript in common are different $(P<0.05)$.

${ }^{\text {Ns }}$ Heterosis is not significant $(P>0.05)$.

*Heterosis is significant $(P<0.05)$.

\section{Prenatal survival of transferred embryos}

The proportion of total transferred embryos carried to term, from data on all recipients receiving embryos, is presented in Table 2 . The overall survival rate was $22.7 \%$. There were no significant differences in survival rate of embryos from $\mathrm{C} 3 \mathrm{H}$ and SWR donors. On the other hand, $\mathrm{C} 3 \mathrm{H}$ recipients exhibited a $117 \%$ increase $(P<0.01)$ relative to SWR mice in ability to maintain survival of transferred embryos to term. Donor $\times$ recipient genotype interaction was not significant. 
Donor heterosis was large $(15 \cdot 6 \%)$ though not significant, while recipient heterosis was negative $(-7 \cdot 5 \%)$ and also not significant.

The overall survival rates from all recipients may be partitioned into two component traits: the proportion of recipients producing litters and the proportion of embryos transferred that were carried to term in recipients which produced litters (Table 2). The overall proportion of females producing litters was $69 \cdot 4 \%$. Embryos from C3H and SWR donors resulted in similar pregnancy rates across recipient genotypes. In contrast, $\mathrm{C} 3 \mathrm{H}$ recipients produced litters at a significantly increased proportion $(99 \% ; P<0.01)$ relative to SWR mice. Donor $\times$ recipient genotype interaction was not significant. Donor heterosis was large $(20.6 \%)$ and recipient heterosis moderate $(9 \cdot 9 \%)$, though neither value was significant.

Table 2. Survival data for reciprocal embryo transfers

\begin{tabular}{|c|c|c|c|}
\hline & $\begin{array}{l}\text { No. of litters } \dagger \\
(\%)\end{array}$ & $\begin{array}{l}\text { Overall } \\
\text { embryo survival }+ \\
(\%)\end{array}$ & $\begin{array}{l}\text { Within-litter } \\
\text { embryo survival } § \\
\quad(\%)\end{array}$ \\
\hline \multicolumn{4}{|c|}{ Donor strain* } \\
\hline $\mathrm{C} 3 \mathrm{H}$ & $13 / 20(65 \cdot 0)^{a}$ & $41 / 209(19 \cdot 6)^{n}$ & $41 / 133(30 \cdot 8)^{a}$ \\
\hline SWR & $10 / 16(62 \cdot 5)^{a}$ & $37 / 162(22 \cdot 8)^{\mathrm{a}}$ & $37 / 128(28 \cdot 9)^{a}$ \\
\hline C3SWF1 & $20 / 26(76.9)^{N S}$ & $75 / 302(24 \cdot 5)^{\mathrm{NS}}$ & $75 / 241(31 \cdot 1)^{\mathrm{NS}}$ \\
\hline \multicolumn{4}{|c|}{ Recipient strain* } \\
\hline $\mathrm{C} 3 \mathrm{H}$ & $17 / 19(89 \cdot 5)^{a}$ & $70 / 224(31 \cdot 3)^{a}$ & $70 / 201(34 \cdot 7)^{a}$ \\
\hline SWR & $9 / 20(45 \cdot 0)^{b}$ & $25 / 224(14.4)^{b}$ & $25 / 96(26 \cdot 0)^{a}$ \\
\hline C3SWF1 & $17 / 23(73.9)^{\mathrm{NS}}$ & $58 / 275(21 \cdot 1)^{\mathrm{NS}}$ & $58 / 204(28 \cdot 4)^{\mathrm{NS}}$ \\
\hline \multicolumn{4}{|c|}{$\begin{array}{l}\text { *Data are for a specific donor genotype across all recipient genotypes or for a specific } \\
\text { recipient genotype across all donor genotypes. }\end{array}$} \\
\hline \multicolumn{4}{|c|}{$\begin{array}{l}\dagger \text { Numerator is number of recipients producing litters, denominator is total number of } \\
\text { recipients. }\end{array}$} \\
\hline \multicolumn{4}{|c|}{$\begin{array}{l}\text { †Data are from all recipients. Numerator is no. of young born, denominator is total } \\
\text { no. of embryos transferred. }\end{array}$} \\
\hline \multicolumn{4}{|c|}{$\begin{array}{l}\text { \$Data are from recipients producing litters. Numerator is no. of young born, denomi- } \\
\text { nator is total no. of embryos transferred. }\end{array}$} \\
\hline \multicolumn{4}{|c|}{$\begin{array}{l}\text { a,b Within columns and for donor and recipient strains separately, parental inbred } \\
\text { strain }(\mathrm{C} 3 \mathrm{H}, \mathrm{SWR}) \text { means with no superscript in common are different }(P<0.05) \\
{ }^{\text {NS }} \text { Heterosis is not significant }(P>0.05) \text {. }\end{array}$} \\
\hline
\end{tabular}

In recipients producing litters, survival rate of transferred embryos was $30 \cdot 5 \%$. No significant differences in survival rates were detected among donor or recipient genotypes, although donor $\times$ recipient genotype interaction approached significance $(P=0.08)$. Donor and recipient heterosis values were small $(4 \cdot 2$ and $-6 \cdot 4 \%$, respectively; $P>0.05)$.

\section{Prenatal growth of transferred embryos}

Body weights and tail lengths of embryo transfer progeny on day of birth are presented in Table 3. Male progeny were significantly heavier than female progeny $(1.60 \mathrm{vs} 1.54 \pm 0.018 \mathrm{~g} ; P<0.05)$, while no sex difference was found for tail length $(12 \cdot 21$ vs $12 \cdot 12 \pm 0 \cdot 11 \mathrm{~mm})$. Progeny from $\mathrm{C} 3 \mathrm{H}$ and SWR donors were not significantly different for either trait. In contrast, $\mathrm{C} 3 \mathrm{H}$ recipients provided a uterine developmental environment which resulted in progeny with significantly larger body weights $(8.6 \% ; P<0.01)$ and longer tail lengths $(4.3 \% ; P<0.05)$ than did SWR recipients. Donor $\times$ recipient genotype interactions were not significant. Donor heterosis was significant for both body weight and tail length (17.3 and $9.9 \%$, respectively; $P<0.001$ ), while recipient heterosis was negligible ( 1.0 and $0 \cdot 1 \%)$. 
Table 3. Least-squares means and s.e. for body weight and tail length at birth of offspring produced by reciprocal embryo transfers

\begin{tabular}{|c|c|c|c|}
\hline & $\begin{array}{l}\text { No. of } \\
\text { young }\end{array}$ & $\begin{array}{l}\text { Body weight } \\
\text { (g) }\end{array}$ & $\begin{array}{l}\text { Tail length } \\
\text { (mm) }\end{array}$ \\
\hline \multicolumn{4}{|c|}{ Donor strain* } \\
\hline C3H & 41 & $1.48 \pm 0.03^{\mathrm{a}}$ & $11 \cdot 7 \pm 0.1^{\mathrm{a}}$ \\
\hline SWR & 37 & $1.50 \pm 0.03^{\mathrm{a}}$ & $11 \cdot 9 \pm 0 \cdot 2^{\mathrm{a}}$ \\
\hline C3SWF1 & 74 & $1.74 \pm 0.02^{* * *}$ & $12 \cdot 9 \pm 0 \cdot 1^{* * *}$ \\
\hline \multicolumn{4}{|c|}{ Recipient strain* } \\
\hline C3H & 70 & $1.63 \pm 0.02^{\mathrm{a}}$ & $12 \cdot 4 \pm 0 \cdot 1^{a}$ \\
\hline SWR & 25 & $1.50 \pm 0.03^{b}$ & $11 \cdot 9 \pm 0 \cdot 2^{b}$ \\
\hline C3SWF1 & 58 & $1.58 \pm 0.02^{\mathrm{NS}}$ & $12 \cdot 2 \pm 0 \cdot 1^{\mathrm{NS}}$ \\
\hline
\end{tabular}

*Data are for a specific donor genotype across all recipient genotypes or for a specific recipient genotype across all donor genotypes, adjusted for litter size by covariance analysis.

${ }^{a, b}$ Within columns and for donor and recipient strains separately, parental inbred strain (C3H, SWR) means with no superscript in common are different $(P<0.05)$.

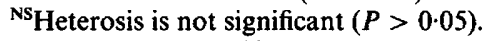

***Heterosis is significant $(P<0 \cdot 001)$.

\section{Histoincompatibility between embryo and uterus}

Survival and prenatal growth of transferred mouse embryos did not appear to be significantly affected by histoincompatibility between embryo and uterus, as suggested by the non-significant donor $\times$ recipient interactions for those traits. However, this interaction did approach significance $(P=0.08)$ for embryo survival rate in recipients producing litters. Linear contrasts revealed that heterozygous C3SWF1 embryos survived at significantly higher rates when developing in partly allogeneic $\mathrm{C} 3 \mathrm{H}$ and SWR uteri as opposed to syngeneic C3SWF1 uteri $(38.6 \%$ vs $22.8 \%$; $P<0.01$ ). Conversely, inbred embryos survived equally well when they developed in uteri of their own genotype or uteri of mice from the other inbred line $(28.9 \%$ vs $25.0 \%)$. An overall contrast of embryos developing in syngeneic vs allogeneic uteri was not significant $(28.6 \% \mathrm{vs} 33.0 \%$; $P=0 \cdot 68$ ).

\section{Discussion}

The present study demonstrates that significant genetic variation exists between two inbred strains of mice in overall survival and prenatal growth of transferred mouse embryos. Partitioning of this variation into donor and recipient effects reveals that the genotype of the developing embryo explains little of the inbred line differences, while the genotype of the uterus providing the developmental environment has significant effects on the embryo's survival and growth. Thus, irrespective of their own genotype, embryos transferred to uteri of mice of the larger strain $(\mathrm{C} 3 \mathrm{H})$ have greater probability of survival to term, larger body weights and longer tail lengths at birth than embryos transferred to uteri of mice of the smaller strain (SWR).

It is of interest to consider the general mechanisms by which uterine genetic differences in overall survival are manifested. $\mathrm{C} 3 \mathrm{H}$ recipients produced significantly higher proportions of litters than did SWR recipients. However, within recipients which produced litters, embryo survival to term was not different among the two inbred strains. It appears that $\mathrm{C} 3 \mathrm{H}$ and SWR mice differ genetically in ability to establish and/or maintain pregnancy, but not in ability to produce offspring once pregnancy is successful. Whether this difference is caused by mechanisms of implantation 
failure or post-implantation death of entire litters is unclear. These results tend to support observations in normally reproducing colonies of these strains, whereby non-productive matings were more frequent in SWR than $\mathrm{C} 3 \mathrm{H}$ mice while litter size of productive matings was similar (W. R. Atchley, unpublished data; Handbook on Genetically Standardized JAX Mice, 1982). The present results illustrate that this strain difference is due to genetic maternal uterine effects and not differential genetic potential of embryos to survive to term.

Several previous reports have investigated relative effects of embryonic and uterine genotypes on survival and prenatal growth in mice, utilizing factorial embryo transfers among inbred strains (Fekete, 1947; Baunack et al., 1986) or genetically selected lines (Brumby, 1960; Moore et al., 1970a, b; Aitken et al., 1977; Al-Murrani \& Roberts, 1978; Moler et al., 1981), or cross-nursing and sib analysis studies (Cox et al., 1959; El-Oksh et al., 1967). In terms of embryo survival, these studies generally indicated a strong maternal uterine genotype effect, while in terms of prenatal growth the relative influences of embryonic and maternal genotypes appear to vary according to the genotypes under study. The present study with the $\mathrm{C} 3 \mathrm{H}$ and SWR inbred strains supports the conclusion that genetic uterine effects have significant influences on prenatal growth while embryonic genotype has relatively smaller effects.

Heterosis, or difference in the mean of the $F_{1}$ compared to the average of the parental lines, was significant only for body weight of recipients at time of transfer and donor (embryo) genotype effects on body weight and tail length of progeny at birth. Donor heterosis effects on overall survival and proportion of recipients producing litters were high (17-21\%), but were not significant. Recipient (uterine) heterosis effects were small and not significant for any of the prenatal survival and growth traits studied. Iida et al. (1987) obtained comparable heterosis results in a similar design employing the random-bred ICR and inbred C57BL lines and their $F_{1}$ cross.

The lack of significant donor or recipient heterosis for embryonic survival is surprising, considering that the crossing of inbred lines should produce progeny which display increases of characters that previously suffered a reduction from inbreeding (Falconer, 1981). However, fairly substantial heterosis values detected in this study may not have been statistically significant due to the relatively small sample sizes.

One additional insight provided by the heterosis results involves the influence of body weight on uterine genotype effects on survival and prenatal growth. Since $\mathrm{C} 3 \mathrm{H}$ mice were both significantly heavier than SWR mice and supported increased overall survival of embryos, it may be postulated that these two results are not independent. However, while the C3SWF1 cross exhibited highly significant heterosis for adult body weight, and, in fact, surpassed $\mathrm{C} 3 \mathrm{H}$ in this trait, no heterosis was detected in uterine genotype effects. This suggests that the heightened body weight of C3SWF 1 had little involvement with the uterine effects in this cross, and that physiological mechanisms other than those related to body weight may be involved in the genetic variation found for these traits.

A potential problem with the interpretation of heterosis results for embryonic and uterine effects on embryo survival concerns the confounding of these effects with possible influences of histoincompatibility between conceptus and mother. Likewise, these same confounding effects pose difficulties in interpretation of effects of histoincompatibility. The only unbiased test available in this study was the effect of an inbred embryo developing in a uterus of the same genotype as opposed to the other inbred uterus, and this proved not to be significant. Many other reports have attempted to address this question in mice (Billington, 1964; James, 1965; Finkel \& Lilly, 1971; Beer et al., 1975; Hetherington, 1978; Hamilton et al., 1985) with conflicting results. These studies were often complicated by heterosis effects or lack of proper statistical adjustment for covariance effects of prenatal fraternity size. The present study finds no consistent evidence for positive or negative effects of histoincompatibility on survival and prenatal growth of transferred mouse embryos.

In conclusion, significant genetic variation among inbred strains was detected in maternal uterine ability to support overall embryo survival and prenatal growth, while no embryonic genotype differences were observed. The uterine effect was due to a higher proportion of $\mathrm{C} 3 \mathrm{H}$ recipients 
maintaining pregnancy to term than SWR recipients. In addition, embryos developing in $\mathrm{C} 3 \mathrm{H}$ uteri achieved larger body weights and longer tail lengths at birth than those developing in SWR uteri. Despite significant body weight differences among recipient genotypes, factors related to body weight did not appear to influence the uterine effect on prenatal survival. It is proposed that mechanisms responsible for the observed effects may operate on processes of implantation and post-implantation mortality of entire litters, and could involve maternal and fetal hormone profiles, utero-placental blood flow and other maternal-fetal interactions. Recipient heterosis was not significant, while donor heterosis was significant for prenatal growth.

Paper No. 11825 of the Journal Series of the North Carolina Agricultural Research Service, Raleigh, NC, 27695-7601. The use of trade names in this publication does not imply endorsement by the North Carolina Agricultural Research Service of the products named, nor criticisms of similar ones not mentioned.

This research was supported in part by NSF grants BSR-860553 and BSR-8605518 to W.R.A. We thank Dr J. H. Britt, Dr B. W. Kirkpatrick and Dr O. W. Robison for critical review of the manuscript.

\section{References}

Aitken, R.J., Bowman, P. \& Gauld, I. (1977) The effect of synchronous and asynchronous egg transfer on foetal weight in mice selected for large and small body size. J. Embryal. exp. Morph. 37, 59-64.

Al-Murrani, W.K. \& Roberts, R.C. (1978) Maternal effects on body weight in mice selected for large and small size. Genet. Res. 32, 295-302.

Atchley, W.R., Newman, S. \& Cowley, D.E. (1988) Genetic divergence in relation to molecular divergence in inbred mice. Genetics, Princeton 120 , 239-253.

Baunack, E., Wieding, B. \& Gartner, K. (1986) Prenatal survival of reciprocal Fl hybrids in inbred mice caused both by embryonic factors and genotype of foster mother. Zuchthygene 21, 115-120.

Beer, A.E., Scott, J.R. \& Billingham, R.E. (1975) Histoincompatibility and maternal immunological status as determinants of fetoplacental weight and litter size in rodents. J. exp. Med. 142, 181-196.

Billington, W.D. (1964) Influence of immunological dissimilarity of mother and foetus on size of placenta in mice. Nature, Lond. 202, 317-318.

Brumby, P.J. (1960) The influence of the maternal environment on growth in mice. Heredity 14, $1-18$.

Cowley, D.E., Pomp, D., Atchley, W.R., Eisen, E.J. \& Hawkins-Brown, D. (1989) The impact of maternal uterine genotype on postnatal growth and adult body size in mice. Genetics, Princeton 122, (in press).

Cox, D.F., Legates, J.E. \& Cockerham, C.C. (1959) Maternal influence on body weight. J. Anim. Sci. 18, 519-527.

El-Oksh, H.A., Sutherland, T.M. \& Williams, J.S. (1967) Prenatal and postnatal maternal influence on growth in mice. Genetics, Princeton 57, 79-94.

Falconer, D.S. (1981) Introduction To Quantitative Genetics, 2nd edn, pp. 230-231, Longman, London.

Fekete, E. (1947) Differences in the effect of uterine environment upon development in the dba and C57 black strains of mice. Anat. Rec. 98, 409-415.

Finkel, S.I. \& Lilly, F. (1971) Influence of histoincompati- bility between mother and foetus on placental size in mice. Nature, Lond. 234, 102-103.

Freeman, M.F. \& Tukey, J.W. (1950) Transformations related to the angular and the square root. Ann. Math Statist. 21, 607-611.

Green, M.C. (1981) Genetic Variants and Strains of the Laboratory Mouse. Gustav Fischer Verlag, New York.

Grizzle, J.E., Starmer, C.F. \& Koch, G.G. (1969) Analysis of categorical data by linear models. Biometrics 25, 489-504.

Hamilton, B.L., Hamilton, A. \& Hamilton, M.S. (1985) Maternal-fetal disparity at multiple minor histocompatibility loci affects the weight of the feto-placental unit in mice. J. Reprod. Immunol. 8, 257-261.

Handbook on Genetically Standardized JAX Mice (1982), 3rd edn, Supplement S:7/82. The Jackson Laboratory, Bar Harbor.

Harvey, W.R. (1979) Least-squares analysis of data with unequal subclass numbers. USDA, ARA H-4, Beltsville.

Hetherington, C.M. (1978) Absence of effect of maternal immunization to paternal antigens on placental weight, fetal weight and litter size in the mouse. $J$. Reprod. Fert. 53, 81-84.

Iida, K., Mizuma, Y. \& Nagai, J. (1987) Heterosis in survival of transferred mouse embryos. Z. Versuchstierkd. 30, 99-103.

James, D.A. (1965) Effects of antigenic dissimilarity between mother and foetus on placental size in mice. Nature, Lond. 205, 613-614.

Lindner, G.M. \& Wright, R.W., Jr (1983) Bovine embryo morphology and evaluation. Theriogenology 20, 407-416.

Moler, T.L., Donahue, S.E., Anderson, G.B. \& Bradford, G.E. (1981) Effects of maternal and embryonic genotype on prenatal survival in two selected mouse lines. J. Anim. Sci. 51, 300-303.

Moore, R.W., Eisen, E.J. \& Ulberg, L.C. (1970a) Genetic and uterine effects on survival in mice selected for body weight. $J$. Reprod. Fert. 23, 271-275. 
Moore, R.W., Eisen, E.J. \& Ulberg, L.C. (1970b) Prenatal and postnatal maternal influences on growth in mice selected for body weight. Genetics, Princeton 64,59-68.
Whitten, W.K. (1971) Nutrient requirement for the culture of pre-implantation embryos in vitro. Adv. Biosci. 6, 129-140.

Received 20 September 1988 